\title{
Exposure to gold nanoparticles produces cardiac tissue damage that depends on the size and duration of exposure
}

\author{
Mohamed Anwar K Abdelhalim
}

\begin{abstract}
Background: Current research focuses on cancer therapy, diagnostics and imaging, although many challenges still need to be solved. However, for the application of gold nanoparticles (GNPs) in therapy and diagnostics it is necessary to know the bioaccumulation and local or systemic toxicity associated to them. The aim of the present study was to investigate the effects of intraperitoneal administration of GNPs on the histological alterations of the heart tissue of rats in an attempt to cover and understand the toxicity and the potential role of GNPs in the therapeutic and diagnostic applications.

Methods: Animals were randomly divided into 3 GNPs-treated rats groups and one control group (CG). The 10, 20 and $50 \mathrm{~nm}$ GNPs were administered intraperitonealy at the rate of 3 or 7 days as follows: Group 1: received infusion of 100 $\mu \mathrm{l}$ GNPs of size $10 \mathrm{~nm}$ for 3 or 7 days; Group 2: received infusion of $100 \mu \mathrm{l}$ GNPs of size $20 \mathrm{~nm}$ for 3 or 7 days; Group 3: received infusion of $100 \mu \mathrm{l}$ GNPs of size $50 \mathrm{~nm}$ for 3 or 7 days. Control group: received no GNPs.

Results: In comparison with the respective control rats, GNPs-treated rat received $100 \mu \mathrm{l}$ of 10 and $20 \mathrm{~nm}$ particles for 3 days or 7 days demonstrating congested heart muscle with prominent dilated blood vessels, scattered and extravasations of red blood cells, focus of muscle hyalinosis, disturbed muscle fascicles, dense prominent focus of inflammatory cells infiltrate by small lymphocytes and few plasma cells while GNPs-treated rat received $100 \mu$ of $50 \mathrm{~nm}$ particles for 3 or 7 days demonstrating benign normal looking heart muscle with normal muscle direction and fascicles, and very few scattered small lymphocytes.

Conclusions: The histological alterations induced by intraperitoneal administration of GNPs were size-dependent with smaller ones induced more affects and related with time exposure of GNPs. This study suggests that interaction of GNPs with proteins and various cell types might be evaluated as part of the toxicological assessment in addition to further experiments related to tissues antioxidant enzymes, oxidative parameters, lipid peroxidation, production of free radicals and/or ROS and cytokine, histomorphologcal and ultrastrucural will be performed to cover and understand the toxicity and the potential use of GNPs as therapeutic and diagnostic tool.
\end{abstract}

Keywords: gold nanoparticles, size, heart muscle, histology, inflammatory, nanotoxicity, cytoplasmic vacuolization, rats

\section{Introduction}

The NPs are being investigated for gene delivery purposes [1-3] and cancer therapy [4]. Data concerning the behavior and toxicity of particles mainly comes from studies on inhaled NPs [5].

Correspondence: abdelhalimmak@yahoo.com

Department of Physics and Astronomy, College of Science, King Saud University, Saudi Arabia
NPs may differ in reactivity and solubility and may interact with all kinds of endogenous proteins, lipids, polysaccharides and cells. A series of tests was proposed for evaluation of the toxicity of NPs used in drug delivery systems [6]. GNPs can easily enter cells and the demonstration that amine and thiol groups bind strongly to GNPs has enabled their surface modification with amino acids and proteins for biomedical applications [7-9]. 
Gold in its bulk form has been considered an inert, noble metal with some therapeutic and medicinal value. GNPs are thought also to be relatively non-cytotoxic [10] while the metallic nature of the metal derived NPs and the presence of transition metals encourages the production of reactive oxygen species (ROS) leading to oxidative stress $[9,11,12]$.

The use of NPs as drug carriers may reduce the toxicity of the incorporated drug [12]. There are differing reports of the extent of the toxic nature of these particles owing to the different modifications of the GNPs, surface functional attachments and shape and diameter size of the NPs $[13,14]$.

The particle size-dependent organ distribution of GNPs has been studied in vivo [15-17]. In vivo studies in rats exposed to aerosols of GNPs revealed that the NPs were rapidly taken into the system with the highest accumulation in the lungs, aorta, esophagus and olfactory bulb [18].

In order to understand and categorize the mechanisms for GNPs toxicity, histological data is needed on the response of living systems to the presence of GNPs of varying size, shape, surface, and exposure duration.

The histological and histochemical characterization of the heart tissues due to GNPs has not been documented and identified before. In the present study, an attempt has been made to characterize the possible histological alterations in the heart tissues after intraperitoneal administration of GNPs and, if so, whether are related to the size of these GNPs and the time of exposure.

\section{Materials and methods Gold nanoparticles}

GNPs of different sizes (10, 20 and $50 \mathrm{~nm}$; products MKN-Au-010, MKN-Au-020 and MKN-Au-050, Canada, respectively) were purchased. All GNPs used in this study were in aqueous solution at a concentration of $0.01 \%$. The mean size and morphology of these GNPs were evaluated from transmission electron microscope (TEM) images.

\section{Animals}

A total of 40 healthy male Wistar-Kyoto rats were obtained from the Laboratory Animal Center (College of Pharmacy, King Saud University, Saudi Arabia). The rats nearly of the same age (12 weeks old) and weighing 220-240 g of King Saud University colony were used. Animals were randomly divided into 3 GNPs-treated rats groups and one control group (CG). The 10, 20 and $50 \mathrm{~nm}$ GNPs were administered intraperitonealy at the rate of 3 or 7 days as follows: Group 1: received infusion of $100 \mu \mathrm{l}$ GNPs of size $10 \mathrm{~nm}$ for 3 or 7 days $(\mathrm{n}=10)$; Group 2: received infusion of $100 \mu \mathrm{l}$ GNPs of size 20 $\mathrm{nm}$ for 3 or 7 days $(\mathrm{n}=10)$; Group 3: received infusion of $100 \mu \mathrm{l}$ GNPs of size $50 \mathrm{~nm}$ for 3 or 7 days $(\mathrm{n}=10)$. Control group: received no GNPs $(\mathrm{n}=10)$.

The rats were maintained on standard laboratory rodent diet pellets and housed in humidity and temperature-controlled ventilated cages on a $12 \mathrm{~h}$ day/night cycle. All experiments were conducted in accordance with the guidelines approved by King Saud University Local Animal Care and Use Committee.

Fresh portions of the heart from each rat were cut rapidly, fixed in neutral buffered formalin (10\%), then dehydrated, with grades of ethanol (70, 80, 90, 95 and $100 \%)$. Dehydration was then followed by clearing the samples in 2 changes of xylene.

Samples were then impregnated with 2 changes of molten paraffin wax, then embedded and blocked out. Paraffin sections (4-5 um) were stained with hematoxylin and eosin (the conventional histological stain) according to Pearse [19]. The bright-field images were acquired using a Nikon Eclipse 800 microscope equipped with a Nikon DXM1200 color CCD camera (Nikon Instruments Inc., Melville, NY). Stained sections of control and treated rats were examined for histological alterations in the heart tissues.

\section{Results and discussions}

\section{Size and morphology of gold nanoparticles}

The 10 and $20 \mathrm{~nm}$ GNPs show spherical shape while 50 nm GNPs show hexagonal shape. The mean size for GNPs was calculated from the images taken by the transmission electron microscope (TEM): The $10 \mathrm{~nm}$ GNPs was of mean size $9.45 \pm 1.33 \mathrm{~nm}, 20 \mathrm{~nm}$ GNPs was of mean size $20.18 \pm 1.80$ and the $50 \mathrm{~nm}$ GNPs was of mean size $50.73 \pm 3.58$ [20-23].

\section{Histological alterations}

No mortality occurred for the administration periods 3 and 7 days of GNPs in any of the experimental groups of the present investigation, and no alterations were observed in the appearance and behavior of GNPs treated rats in comparison with the control ones.

Control group (Figure 1): Microscopic pictures show GNPs-normal rat demonstrating benign blunt looking heart muscle of different heart muscle directions and with no pathological findings.

In comparison with the control group, the following histological alterations were detected in the heart tissue of GNPs-treated rats. These histological alterations were observed in Figures 2, 3, 4, 5, 6, 7 and can be summarized as follows:

1) GNPs-treated rat received $100 \mu \mathrm{l}$ of $10 \mathrm{~nm}$ particles for 3 days demonstrating heart muscle with prominent dilated congested blood vessels, scattered and extravasations of red blood cells and few small lymphocytic infiltrate as shown in Figure 2 


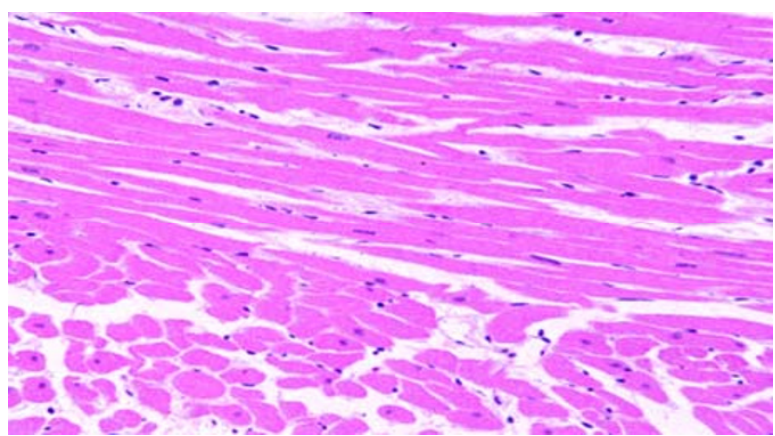

$(40 \times 8)$

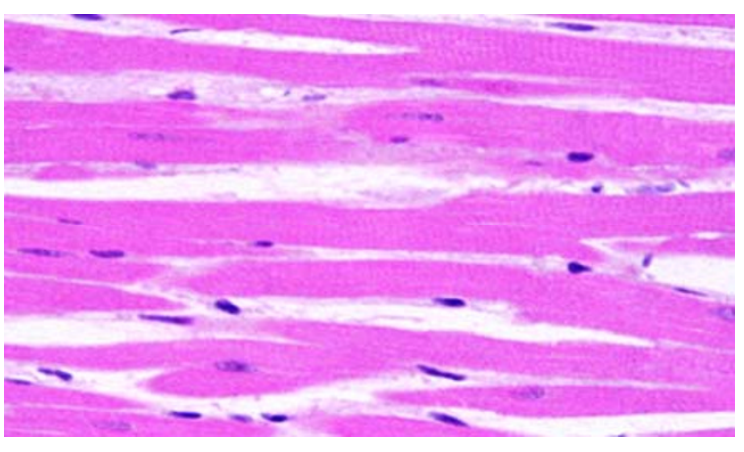

$(100 \times 2)$

Figure $1 \mathrm{GNPs}$-normal rat demonstrating normal heart muscle

2) GNPs-treated rat received $100 \mu \mathrm{l}$ of $10 \mathrm{~nm}$ particles for 7 days demonstrating scattered and extravasations of red blood cells, congested dilated blood vessels, prominent focus of small lymphocytic infiltrate, focus of muscle hyalinosis, disturbed muscle fascicles as shown in Figure 3.
3) GNPs-treated rat received $100 \mu \mathrm{l}$ of $20 \mathrm{~nm}$ particles for 3 days demonstrating dense prominent focus of inflammatory cells infiltrate by small lymphocytes, few plasma cells, prominent congested dilated blood vessels and few scattered extravasations of red blood cells as shown in Figure 4.

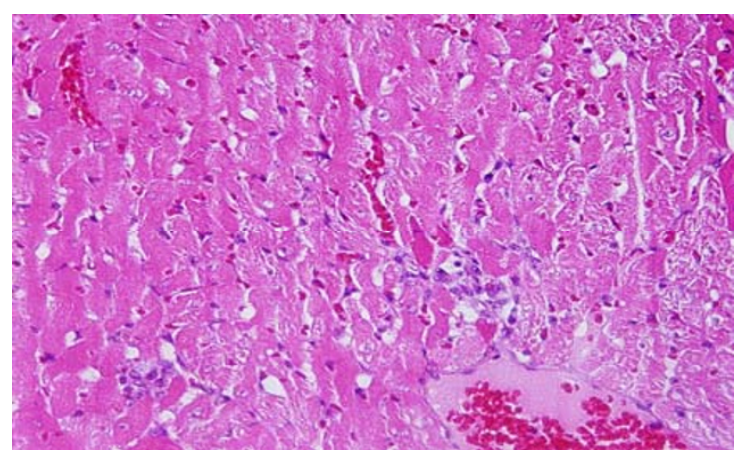

$(40 \times 4)$

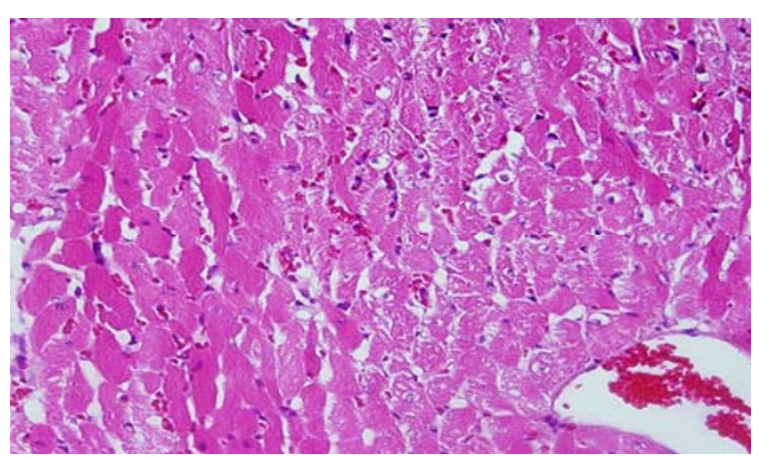

$(40 \times 5)$

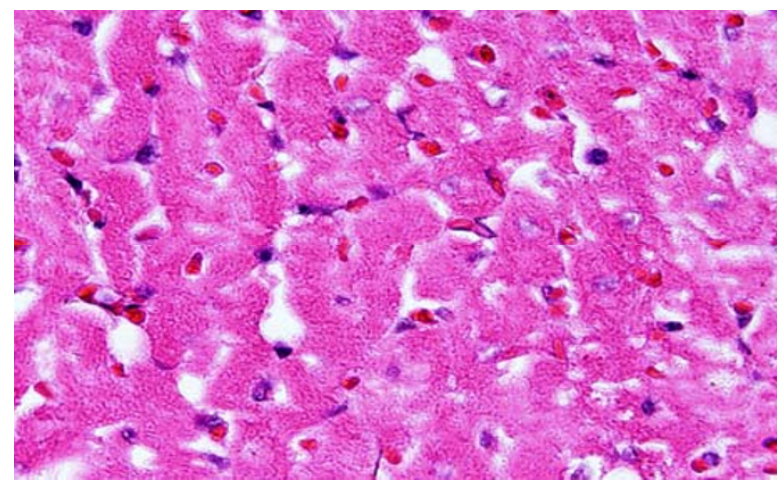

(100 x 1)

Figure 2 GNPs-treated rat received $100 \mu \mathrm{l}$ of $10 \mathrm{~nm}$ particles for 3 days demonstrating heart muscle with prominent dilated congested blood vessels, scattered and extravasations of red blood cells and few small lymphocytic infiltrate. 


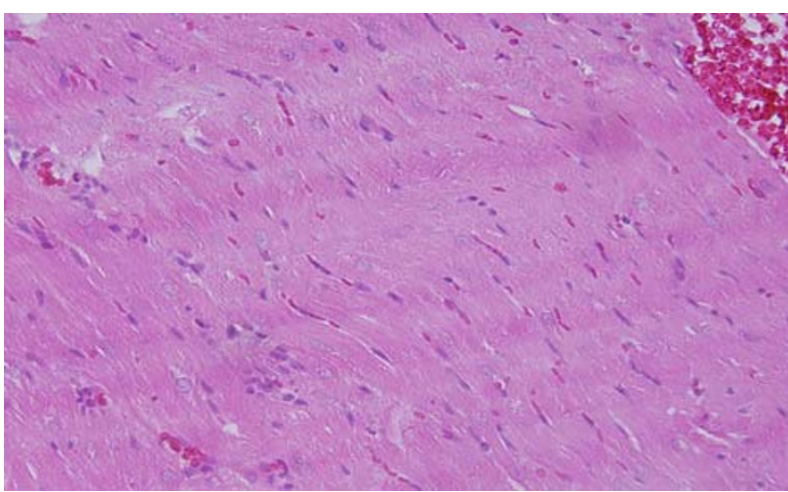

(A: $40 \times 7)$

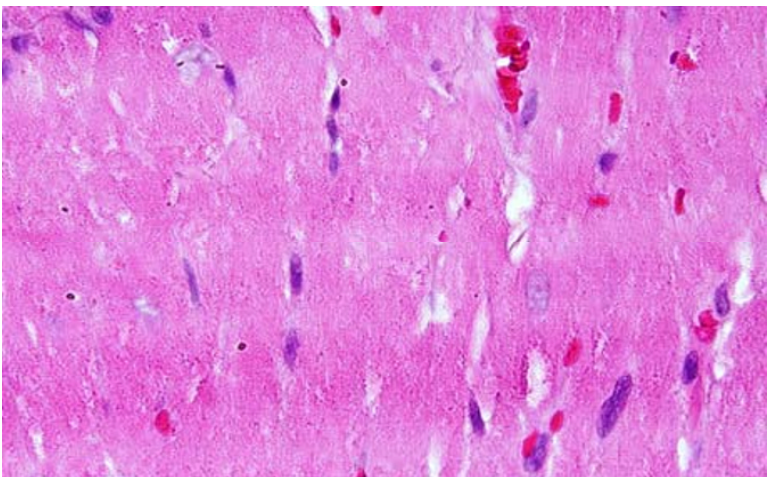

$(C: 100 \times 7)$

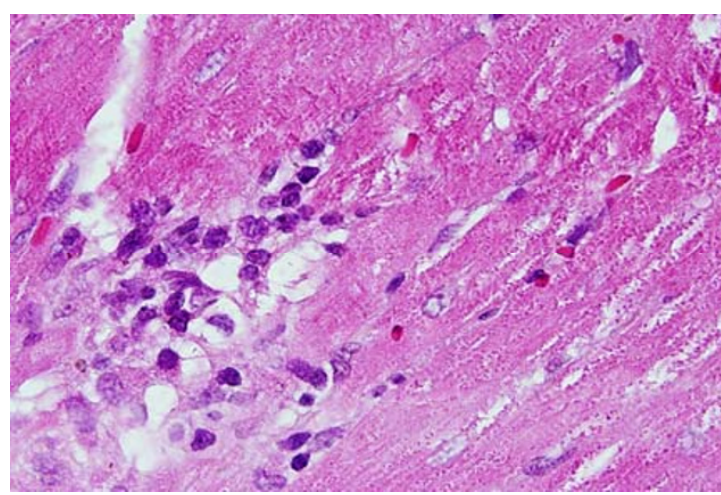

(B: $100 \times 1)$

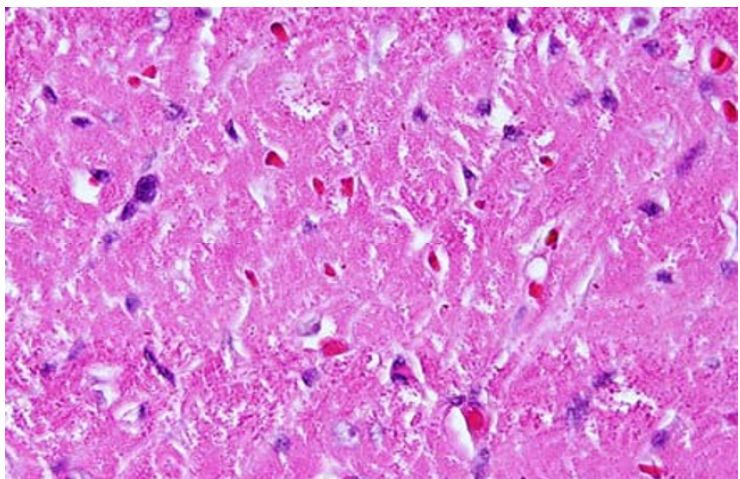

(D: $100 \times 8$ )

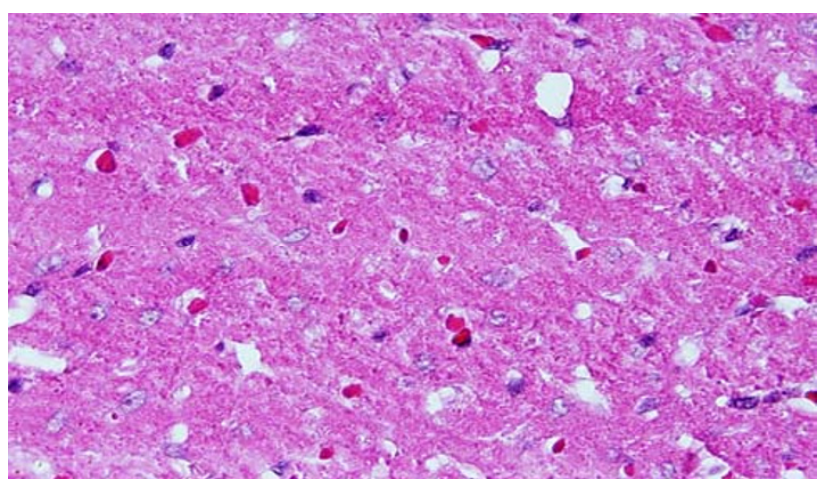

\section{(E: $100 \times 9)$}

Figure $3 \mathrm{GNPs}$-treated rat received $100 \mu \mathrm{l}$ of $10 \mathrm{~nm}$ particles for 7 days demonstrating scattered and extravasations of red blood cells, congested dilated blood vessels, prominent focus of small lymphocytic infiltrate associated with focus of muscle hyalinosis, disturbed muscle fascicles and scattered red blood cells.

4) GNPs-treated rat received $100 \mu \mathrm{l}$ of $20 \mathrm{~nm}$ particles for 7 days demonstrating dense chronic inflammatory cells infiltrate with extravasations of red blood cells as shown in Figure 5.

5) GNPs-treated rat received $100 \mu \mathrm{l}$ of $50 \mathrm{~nm}$ particles for 3 days demonstrating benign normal looking heart muscle with normal muscle direction and fascicles with no pathological effect as shown in Figure 6

6) GNPs-treated rat received $100 \mu \mathrm{l}$ of $50 \mathrm{~nm}$ particles for 7 days demonstrating benign normal looking heart muscle, very few scattered small lymphocytes as shown in Figure 7. 


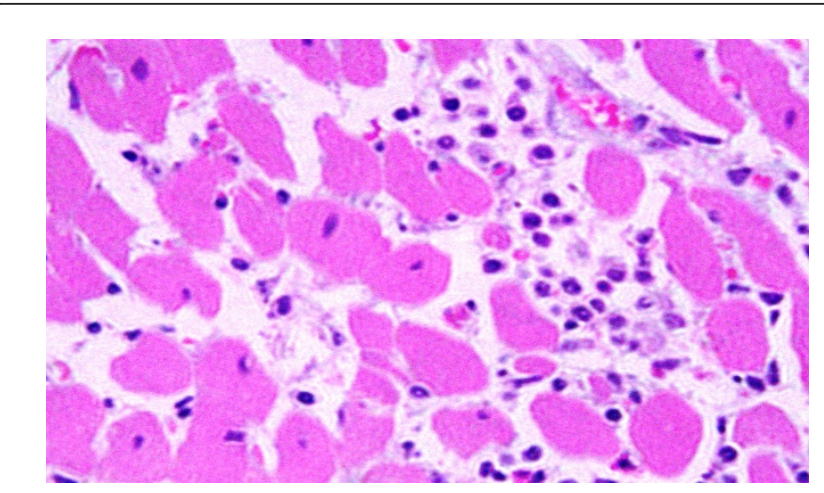

(A: $100 \times 1)$

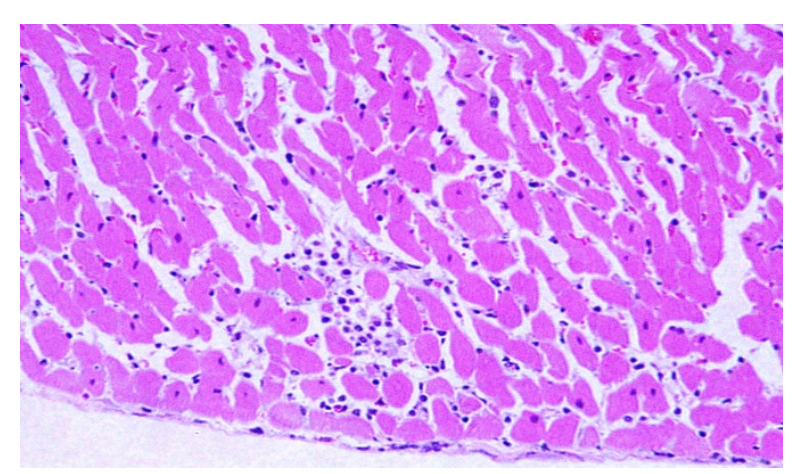

(B: $40 \times 8)$

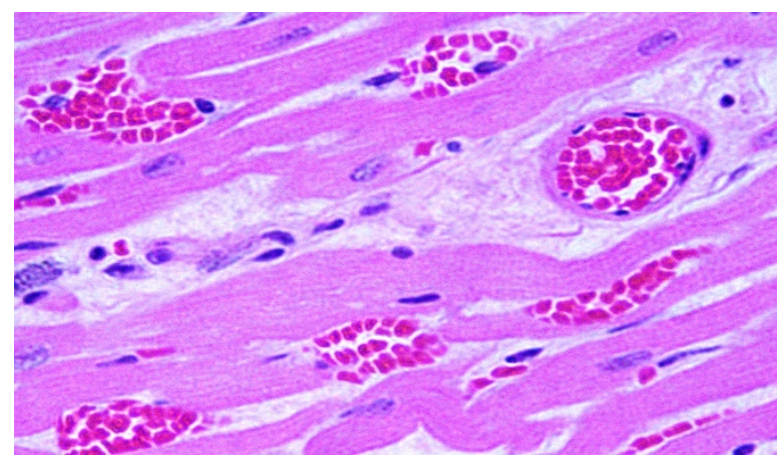

\section{(C: $100 \times 6)$}

Figure 4 GNPs-treated rat received $100 \mu \mathrm{l}$ of $20 \mathrm{~nm}$ particles for 3 days demonstrating dense prominent focus of inflammatory cells infiltrate of small lymphocytes and few plasma cells and prominent congested dilated blood vessels and few scattered extravasation red blood cells.

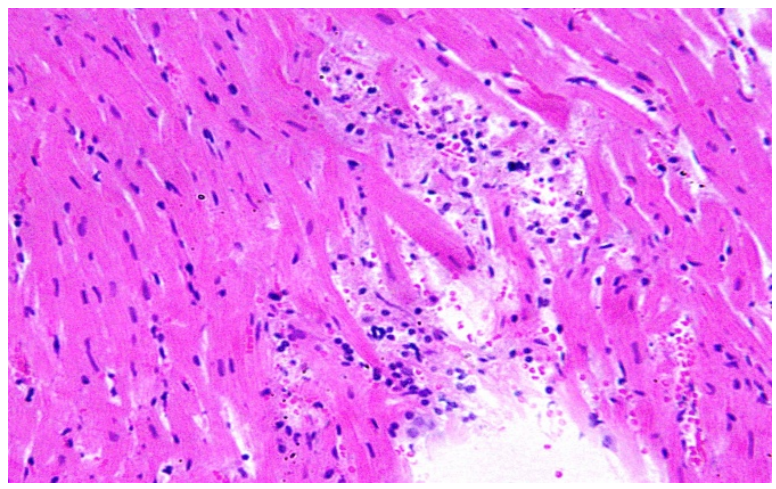

(40 $\times 1)$

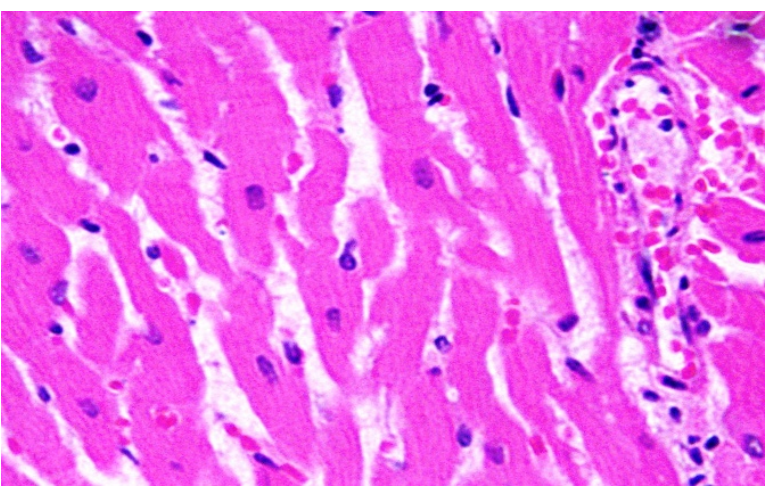

(100 x 9)

Figure 5 GNPs-treated rat received $100 \mu \mathrm{l}$ of $20 \mathrm{~nm}$ particles for 7 days demonstrating dense chronic inflammatory cells infiltrate with extravasation of red blood cells. 


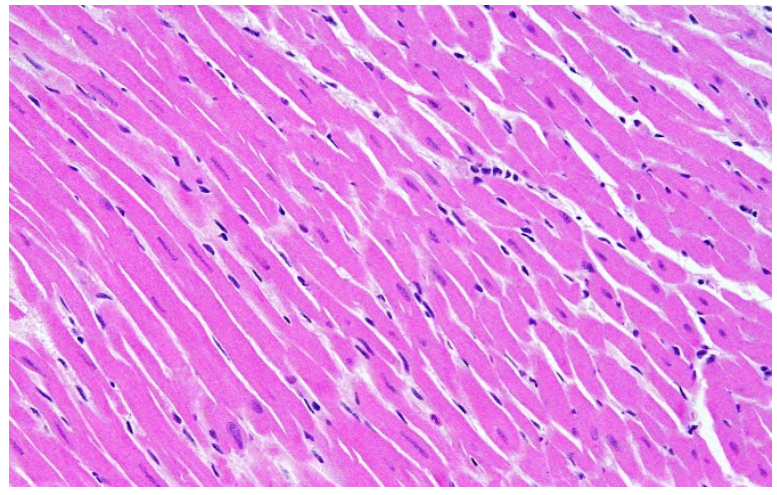

(40 $\times 5)$

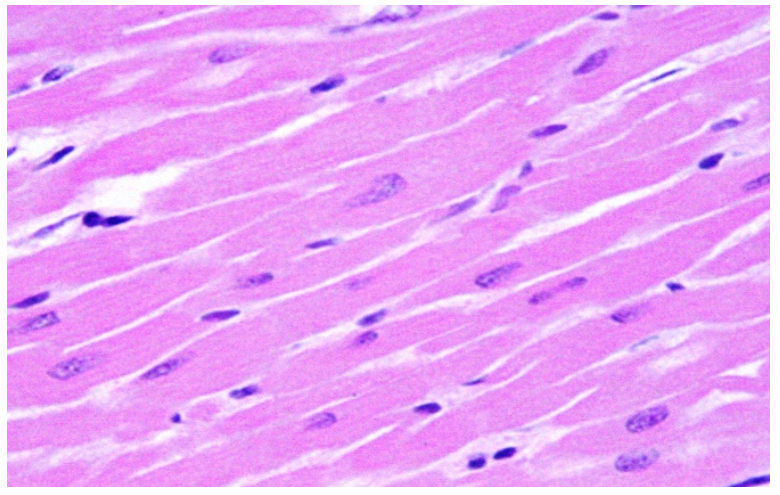

$(100 \times 4)$

Figure 6 GNPs-treated rat received $100 \mu \mathrm{l}$ of $50 \mathrm{~nm}$ particles for 3 days demonstrating benign normal looking heart muscle with normal muscle direction and fascicles with no pathological effect.

The histological heart alterations induced by intraperitoneal administration of GNPs were size-dependent with smaller ones induced more affects and related with time exposure of GNPs.

This infiltration of GNPs was more prominent after 7 days of administration and in rats received 10 and 20 $\mathrm{nm}$ GNPs than those received $50 \mathrm{~nm}$ GNPs. The histological heart alterations may suggest that GNPs could interfere with the antioxidant defense mechanism and leading to reactive oxygen species (ROS) generation which in turn may imitate an inflammatory response. Inflammatory cells infiltration was seen in the portal triads and the perioral zones of GNPs treated rats. The infiltrate cells were mainly lymphocytes and plasma cells [20-23].
GNPs were more strongly oxidizing as evidenced by lipid peroxidation $[24,25]$ as well as decreased neutral red retention time (NRRT) and numbers of thiol-containing proteins evident in electrophoretic separations. Cadmium may displace iron or copper from metalloproteins leading to oxidative stress via the Fenton reaction [26].

It has been reported that $5 \mathrm{~nm}$ GNPs caused significantly greater oxidative stress and cytotoxicity effects than larger ones [27-29]. The $5 \mathrm{~nm}$ GNPs have shown to catalyze nitric oxide (NO) production from endogenous S-nitroso adducts with thiol groups in blood serum. NO reacts rapidly with superoxide producing peroxynitrite (ONOO-) which can interact with lipids, DNA, and proteins via direct oxidative reactions or via indirect

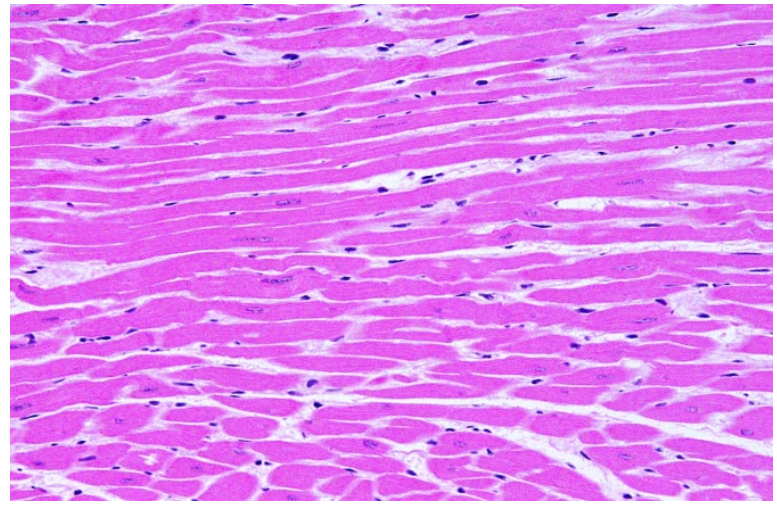

(40 x 4)

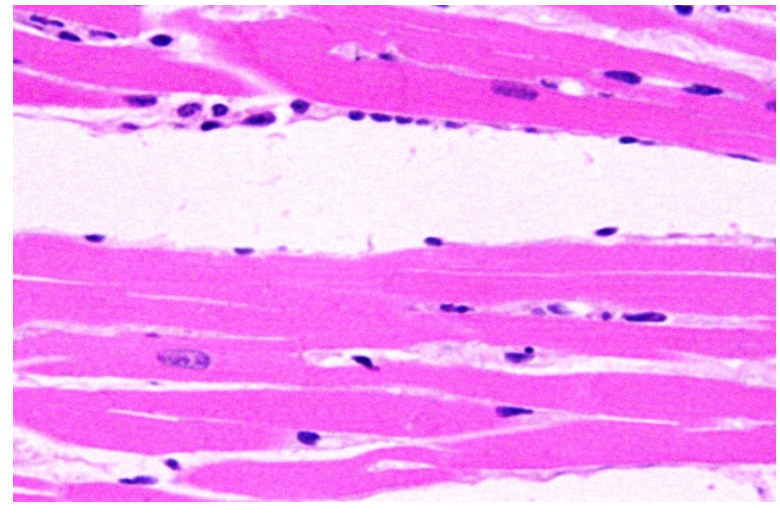

(100 x 8)

Figure $7 \mathrm{GNPs}$-treated rat received $100 \mu \mathrm{l}$ of $50 \mathrm{~nm}$ particles for 7 days demonstrating benign normal looking heart muscle, very few scattered small lymphocytes with no any other pathological effect. 
radical-mediated damage [28]. ROS production could result from the proportionately high surface area of GNPs used in this investigation [30,31].

Several possible mechanisms of action for the toxicity of particles including injury of epithelial tissue [31], inflammation, and oxidative stress response [32,33]. At the cellular level oxidative stress is considered to be of importance [34,35]. Nanoparticle induced oxidative stress responses in keratinocytes, macrophages and blood monocytes after in vitro exposure [36,37].

NPs are nearly of same dimensions as some biological molecules such as proteins and nucleic acids. Many of these biomolecules consist of long macromolecular chains which are folded and shaped by cooperative and weak interaction between side groups. The GNPs may intrude into these complex folded structures.

GNPs activate the phagocytic activity of the sinusoidal cells by increasing the number of Kupffte cells to help in removing the accumulated GNPs where lysosomes are involved in the intracellular breakdown into small metabolic products. The produced Kupffer cells hyperplasia might be correlated with the amount of injurious to the hepatic tissue induced by GNPs intoxication and represents a defense mechanism of detoxification. Kupffer cell hyperplasia is contributed to hepatic oxidative stress [20-23,38].

This scattered cytoplasmic vacuolization might indicate toxicity effect that exhibited as a result of disturbances of membranes function which leads to massive influx of water and $\mathrm{Na}^{+}$due to GNPS effects. Cellular swelling might be accompanied by leakage of lysosomal hydrolytic enzymes that lead to cytoplasmic degeneration and macromolecular crowding [39].

Fatty change was observed in some swelling hepatocytes of rats exposed to $100 \mu \mathrm{l}$ of $10 \mathrm{~nm}$ GNPs and to lesser extent in the ones exposed to larger particles. This hepatic liposis was more prominent in rat exposed to GNPs for 7 days than those received the treatment for 3 days [20-23]. Hepatocytes fatty change might be due to lipid peroxidation that leads to rough endoplasmic damage and detachment of the cytoplasmic lipoprotein which indicate abnormal fat metabolism [22,25-27].

The rats received 10 and $20 \mathrm{~nm}$ GNPs showed hemorrhage and excess extravasation of red blood cells. Less disruption was observed in rats exposed to $50 \mathrm{~nm}$ GNPs while more damage was detected after 7 days than 3 days of GNPs exposure. This alteration might indicate heart muscle damage and congestion by GNPs exposure.

None of the above alterations were observed in the heart muscle of any member of the control group.

The interaction of NPs with living systems is also affected by the characteristic dimensions. As noted above, GNPs, of smaller size, may reach inside biomolecules, a situation not possible for larger GNPs. It has been reported that inhaled NPs reach the blood and may reach other target sites such as the liver, heart or blood cells $[40,41]$.

Reduction in size results in an enormous increase of surface to volume ratio, so relatively more molecules of the chemical are present on the surface, thus enhancing the intrinsic toxicity. This may be one of the reasons that smaller GNPs are generally more toxic than larger particles of the same insoluble material when compared on a mass dose base [42].

In the present study we have not measured GNPs concentration in urine and feces, but this point will be taken into our consideration in other new additional experiments.

Further experiments related to tissues antioxidant enzymes, oxidative parameters, lipid peroxidation, production of free radicals and/or ROS and cytokine, histomorphologcal and ultrastrucural will be performed to cover and understand the toxicity and the potential use of GNPs as therapeutic and diagnostic tool.

\section{Conclusions}

In comparison with the respective control rats, histological alterations induced in the heart tissue exposure could be an indication of congested heart muscle with dilated blood vessels, extravasations of red blood cells, muscle hyalinosis, disturbed muscle fascicles, inflammatory cells infiltrate by small lymphocytes and plasma cells due to GNPs toxicity that became unable to deal with the accumulated residues resulting from metabolic and structural disturbances caused by these particles. One might conclude that these alterations are sizedependent with smaller ones induced more damage with relation to the time exposure of GNPs.

The GNPs-treated rat received $100 \mu \mathrm{l}$ of $50 \mathrm{~nm}$ particles for 3 or 7 days demonstrating benign normal looking heart muscle with normal muscle direction and fascicles, very few scattered small lymphocytes, and with no other pathological effects.

One mechanism of toxicity of NPs is likely to be induction of ROS and the consequential oxidative stress in cells and organs. The appearance of congested heart muscle with prominent dilated blood vessels and focus of inflammatory cells infiltrate by small lymphocytes and plasma cells may suggest that GNPs interact with proteins and enzymes of the hepatic tissue interfering with the antioxidant defense mechanism and leading to reactive oxygen species (ROS) generation which in turn may induce stress.

\section{Acknowledgements}

The author is very grateful to the National Plan of Science and Technology (NPST). This research was financially supported by the National Science and Technology Innovation Plan (NSTIP), Research No. 08-ADV206-02 and 
Research No. 09-NAN670-02, College of Science, King Saud University, Saudi Arabia.

\section{Authors' contributions}

AMAK has analyzed data, interpreted and written the final draft of this manuscript. The animal model used in this study was obtained from the Laboratory Animal Center (College of Pharmacy, King Saud University, Saudi Arabia). AMAK has conceived the study and its design and obtained research grants for this study. The authors have read and approved the final manuscript.

\section{Competing interests}

The author declares that he has no competing interests.

Received: 8 October 2011 Accepted: 10 November 2011

Published: 10 November 2011

\section{References}

1. Gemeinhart RA, Luo D, Saltzman WM: Cellular fate of modular DNA delivery system mediated by silica nanoparticles. Biotechn Prog 2005, 21:532-537.

2. Yoo HS, Lee JE, Chung H, Kwon IC, Jeong SY: Self-assembled nanoparticles containing hydrophobically modified glycol chitosan for gene delivery. J Control Release 2005, 103:235-243.

3. Roy I, Ohulchanskyy TY, Bharali DJ, Pudavar HE, Mistretta RA, Kaur N, Prasad PN: Optimal tracking of organically modfied silica nanoparticles as DNA carriers: a nonviral, nanomedicine approach for gene delivery. Proc Natl Acad Sci USA 2005, 102:297-284.

4. Gordon EM, Hall FL: Nanotechnology blooms, at last. Oncol Rep 2005, 13:1003-1007.

5. Oberdörster G, Oberdörster E, Oberdörster J: Nanotoxicology: An emerging discipline evolving from studies of ultrafine particles. Environ Health Perspect 2005, 113:823-839.

6. Borm PJ, Kreyling WG: Toxicological hazards of inhaled nanoparticles potential implications for drug delivery. J Nanoscience Nanotechnol 2004 4:521-531

7. Connor EE, Mwamuka J, Gole A, Murphy CJ, Wyatt MD: Gold nanoparticles are taken up by human cells but do not cause acute cytotoxicity. Small 2005, 1:325-327.

8. Dani RK, Kang M, Kalita M, Smith PE, Bossmann SH, Chikan V: MspA poringold nanoparticle assemblies: enhanced binding through a controlled cysteine mutation. Nano Lett 2008, 8:1229-1236.

9. Schellenberger EA, Reynolds F, Weissleder R, Josephson L: Surfacefunctionalized nanoparticle library yields probes for apoptotic cells. Chembiochem 2004, 5:275-279.

10. MacNee W, Donaldson K: Mechanism of lung injury caused by PM10 and ultrafine particles with special reference to COPD. Eur Respir J 2003, 40:47S-51S.

11. Jia HY, Liu Y, Zhang XJ, Han L, Du LB, Tian Q, YC X: Potential oxidative stress of gold Nanoparticles by induced-NO releasing in serum. $J$ am Chem Soc 2009, 131(1):40-1.

12. Kim SY, Lee YM, Baik DJ, Kang JS: Toxic characteristics of methoxy poly (ethylene glycol)/poly( $\varepsilon$-caprolactone) nanospheres; in vitro and in vivo studies in the normal mice. Biomaterials 2003, 24:55-63.

13. Takahashi H, Niidome $Y$, Niidome T, Kaneko K, Kawasaki H, Yamada S: Modification of gold nanorods using phosphatidylcholineto reduce cytotoxicity. Langmuir 2006, 22(1):2-5

14. Pan $Y$, Neuss S, Leifert A, Fischler M, Wen F, Simon U, Schmid G, Brandau W, Jahnen-Dechent W: Size-dependent cytotoxicity of gold nanoparticles. Small 2007, 3(11):1941-1949.

15. BarathManiKanth S, Kalishwaralal K, Sriram M, Pandian SRK, Youn H, Eom S, Gurunathan G: Anti-oxidant effect of gold nanoparticles restrains hyperglycemic conditions in diabetic mice. Journal of Nanobiotechnology 2010, 8:16.

16. Hussain SM, Hess KL, Gearhart JM, Geiss KT, Schlager JJ: In vitro toxicity of nanoparticles in BRL-3A rat liver cells. Toxicol in Vitro 2005, 19.975-983.

17. Schrand AM, Bradich-Stolle LK, Schlager JJ, Dai L, Hussain SM: Can silver nanoparticles be useful as potential biological labels? Nanotechnology 2008, 9:1-13.
18. Lanone S, Boczkowski J: Biomedical applications and potential health risks of nanomaterials: molecular mechanisms. Curr Mol Med 2006, 6:651-63.

19. Pearse AE: Histochemistry. Theoritical and applied. Analytical technology. Churchill-Livingstone, Edinburgh; 419852.

20. Abdelhalim MAK, Jarrar BM: Gold nanoparticles administration induced prominent inflammatory, central vein intima disruption, fatty change and Kupffer cells hyperplasia. Lipids in Health and Disease 2011, 10:133.

21. Abdelhalim MAK, Jarrar BM: The appearance of renal cells cytoplasmic degeneration and nuclear destruction might be an indication of GNPs toxicity. Lipids in Health and Disease 2011, 10:147.

22. Abdelhalim MAK, Jarrar BM: Renal tissue alterations were size-dependent with smaller ones induced more effects and related with time exposure of gold nanoparticles. Lipids in Health and Disease 2011, 10:163.

23. Abdelhalim MAK, BM : Gold nanoparticles induced cloudy swelling to hydropic degeneration, cytoplasmic hyaline vacuolation, polymorphism, binucleation, karyopyknosis, karyolysis, karyorrhexis and necrosis in the liver. Lipids in Health and Disease 2011, 10:166.

24. Reddy JK, Rao MS: Lipid metabolism and liver inflammation. II. Fatty liver disease and fatty acid oxidation. Am J Physiol Gastrointest Liver Physiol 2006, 290(5):G852-8

25. Tedescoa S, Doyleb H, Blascoc J, Redmondb G, Sheehana D: Oxidative stress and toxicity of gold nanoparticles in Mytilus edulis. Aquatic Toxicology 2010, 100:178-186.

26. Senaratne RH, De Silva AD, Williams SJ, Mougous JD, Reader JR, Zhang TJ, Chan S, Sidders B, Lee DH, Chan J, Bertozzi CR, Riley LW: 5'Adenosinephosphosulphate reductase $(\mathrm{CysH})$ protects Mycobacterium tuberculosis against free radicals during chronic infection phase in mice. Mol Microbiol 2006, 59:1744-1753.

27. Pan Y, Leifert A, Ruau D, Neuss S, Bornemann J, Schmid G, Wolfgang B, Ulrich S, Willi J-D: Gold nanoparticles of diameter $1.4 \mathrm{~nm}$ trigger necrosis by oxidative stress and mitochondrial damage. Small 2009, 5:2067-2076.

28. Lasagna-Reeves C, Gonzalez-Romero D, Barria MA, Olmedo I, Clos A, Sadagopa Ramanujam VM, Urayama A, Vergara L, Kogan MJ, Soto C: Bioaccumulation and toxicity of gold nanoparticles after repeated administration in mice. Biochemical and Biophysical Research Communications 2010, 393:649-655.

29. Lasagna-Reeves C, Gonzalez-Romero D, Barria MA, Olmedo I, Clos A Sadagopa Ramanujam VM, Urayama A, Vergara L, Kogan MJ, Soto C: Bioaccumulation and toxicity of gold nanoparticles after repeated administration in mice. Biochemical and Biophysical Research Communications 2010, 393:649-655.

30. Nel A, Xia T, Mädler L, Li N: Toxic potential of materials at the nanolevel. Science 2006, 311:622-627.

31. Pagan I, Costa DL, McGee JK, Richards JH, Dye JA: Metals mimic airway epithelial injury induced by in vitro exposure to Utah Valley ambient particulate matter extracts. J Toxicol Environ Health 2003, 66A:1087-1112.

32. Nel AE, Diaz-Sanchez D, Li N: The role of particulate pollutants in pulmonary inflammation and asthma: Evidence for the involvement of organic chemicals and oxidative stress. Curr Opin Pulmon Med 2001, 7:20-26

33. Donaldson K, Stone V: Current hypotheses on the mechanism of toxicity of ultrafine particles. Ann Ist Super Sanità 2003, 39:405-410.

34. Donaldson K, Stone V, Clouter A, Renwick L, MacNee W: Ultrafine particles. Occup Environ Med 2001, 58:211-216.

35. Oberdörster G, Oberdörster E, Oberdörster J: Nanotoxicology: An emerging discipline evolving from studies of ultrafine particles. Environ Health Perspect 2005, 113:823-839.

36. Shvedova AA, Castranova V, Kisin ER, Schwegler-Berry D, Murray AR, Gandelsman VZ, Maynard A, Baron P: Exposure to carbon nanotuibe material: assessment of nanotube cytoyoxicity using human keratinocyte cells. J Toxicol Environ Health 2003, 66A:1909-1926.

37. Brown DM, Wilson MR, MacNee W, Stone V, Donaldson K: Size dependent proinflammatory effects of ultrafine polystyrene particles: a role for surface area and oxidative stress in the enhanced activity of ultrafines. Toxicol Appl Pharmacol 2001, 175:191-199.

38. Neyrinck A: Modulation of Kupffer cell activity: physio-pathological consequences on hepatic metabolism. Bull Mem Acad R Med Belg 2004, 159(5-6):358-66 
39. Del Monte U: Swelling of hepatocytes injured by oxidative stress suggests pathological changes related to macromolecular crowding. Medical Hypotheses 2005, 64(4):818-825.

40. Oberdörster G, Sharp Z, Atudorei V, Elder ACP, Gelein R, Lunts A, Kreyling W, Cox C: Extrapulmonary translocation of ultrafine carbon particles following whole-body inhalation exposure of rats. J Toxicol Environ Health 2002, 65A:1531-1543.

41. Kreyling WG, Semmler M, Erbe F, Mayer P, Takenaka S, Schulz H, Oberdörster $\mathrm{G}$, Ziesenis A: Translocation of ultrafine insoluble iridium particles from lung epithelium to extrapulmonary organs is size dependent but very low. J Toxicol Environ Health 2002, 65(Part A):1513-1530.

42. Donaldson K, Stone V, Tran CL, Kreyling W, Borm PJA: Nanotoxicology. Occup Environ Med 2004, 61:727-728.

doi:10.1186/1476-511X-10-205

Cite this article as: Abdelhalim: Exposure to gold nanoparticles

produces cardiac tissue damage that depends on the size and duration of exposure. Lipids in Health and Disease 2011 10:205.

\section{Submit your next manuscript to BioMed Central} and take full advantage of:

- Convenient online submission

- Thorough peer review

- No space constraints or color figure charges

- Immediate publication on acceptance

- Inclusion in PubMed, CAS, Scopus and Google Scholar

- Research which is freely available for redistribution

Submit your manuscript at www.biomedcentral.com/submit 